\title{
The methodology for assessing the host range of a potential paropsine parasitoid Eadya paropsidis (Braconidae)
}

\author{
T.M. Withers ${ }^{1}$, G.R. Allen ${ }^{2}$ and A.R. Pugh ${ }^{1}$ \\ ${ }^{1}$ Scion, Private Bag 3020, Rotorua 3046, New Zealand \\ ${ }^{2}$ School of Land \& Food/TIA, University of Tasmania, Hobart TAS 7001, Australia, \\ Corresponding author: toni.withers@scionresearch.com
}

Classical biological control is being attempted for Paropsis charybdis (Coleoptera: Chrysomelidae: Chrysomelinae), an Australian eucalypt pest established in New Zealand. The Australian solitary larval endoparasitoid Eadya paropsidis (Hymenoptera: Braconidae) is under investigation. Leaf-feeding larvae of closely-related chrysomelid non-target species for host range testing were examined against E. paropsidis using various assays. Detailed behavioural observations of E. paropsidis were undertaken during: 1) No-choice sequential assays of the A-B alternating with B-A type (where A is the target P. charybdis, and B is the non-target species); and 2) Two-choice assays of the A+B type. 3) In addition, groups of non-target larvae were exposed to E. paropsidis under no-choice conditions for 24 hours, then reared for survival to ascertain the physiological development of any parasitoid lifestages. In all cases, survival and development parameters of non-targets species were compared to the target $P$. charybdis.

\section{February/March moth flights in Manawatu have important implications for porina management}

\author{
C.M. Ferguson ${ }^{1}$, M.A. Gee-Taylor ${ }^{2}$ and N.K. Richards ${ }^{3}$ \\ ${ }^{1}$ AgResearch, Invermay Agriculture Centre, Private Bag 50034, Mosgiel 9053, New Zealand \\ ${ }^{2}$ Glencorran Station, RD 54, Kimbolton 4774, New Zealand \\ ${ }^{3}$ AgResearch, Lincoln Science Centre, Private Bag 4749, Christchurch 8140, New Zealand \\ Corresponding author: colin.ferguson@agresearch.co.nz
}

Porina (Wiseana spp.), a complex of seven species, three with two haplotypes, are intractable pests on many New Zealand farms. Regional differences in species composition and timing of caterpillar development impact on porina control. At Glencorran Station, Manawatu, porina moth flights were monitored using a light trap from 2012/13 to 2015/16. The most common species trapped was W. copularis. W. signata was also regularly collected. Both species flew from October to March but the main flight period occurred in late February/ early March and consisted almost entirely of northern haplotype W. copularis. The time of peak flight means the most cost effective control strategy, application of diflubenzuron against young caterpillars, should be undertaken in June several months later than traditionally considered for most porina prone areas. Furthermore, caterpillars from the late flights, will attain large size in July/August which may coincide with low porina feeding deterrent and toxin production by the AR37 ryegrass endophyte. Consequently, when caterpillars are most voracious, protection of ryegrass plants by the endophyte is at a low ebb and may help explain why some AR37 ryegrass pastures, especially in colder areas, are damaged by porina. 